\title{
Novel Methods to Incorporate Deuterium in the MOS Structures
}

\author{
M. H. Lee, C.-H. Lin, and C. W. Liu, Senior Member, IEEE
}

\begin{abstract}
The deuterium concentration as high as $2 \times 10^{20}$ $\mathrm{cm}^{-3}$ can be incorporated in rapid thermal oxide layers by a process of deuterium prebake and deuterium post oxidation anneal. The deuterium distributed not only at $\mathrm{Si} /$ oxide interface but also in the bulk oxide. The deuterium incorporation shows the improvement on soft breakdown characteristics and the interface state density at $\mathrm{SiO}_{2} / \mathrm{Si}$ after stress. The addition of very high vacuum prebake process yields a deuterium concentration of $9 \times$ $10^{20} \mathrm{~cm}^{-3}$, but also leads to the formation of rough oxide.
\end{abstract}

Index Terms-Deuterium incorporation, interface states, MOS, very high vacuum prebake.

\section{INTRODUCTION}

$\mathbf{T}$ $\checkmark$ HE ELECTRICAL degradation of metal-oxide-silicon (MOS) devices due to electrical stress has been extensively studied since the early 1980s [1]. Some degradation is related to the hydrogen release from the $\mathrm{Si} /$ oxide interface by hot electrons [2] and the incorporation of deuterium at the Si/oxide interface can significantly improve the device reliability [3]. The strong coupling between Si-D bond bending mode $\left(460 \mathrm{~cm}^{-1}\right)$ and transverse optical phonons in bulk $\mathrm{Si}\left(463 \mathrm{~cm}^{-1}\right)$ is responsible for this giant isotope effect [4]-[6]. Recently, we have demonstrated that the deuterium incorporation can improve the soft breakdown in the NMOS tunneling diodes [7] and the reliability of MOS tunneling light emitting diodes [8]. The conventional method to incorporate the deuterium is performed by post metallization anneal after gate electrode deposition. In this letter, we report three kinds of deuterium process performed before the gate electrode deposition, and compare the deuterium concentrations with each process. The improvement of electrical properties is also demonstrated.

\section{GROWTH AND FABRICATION}

The 4-in p-type wafer was transferred to the process chamber through the load-lock chamber and the ultrathin gate oxide of the NMOS diode was grown by rapid thermal oxidation (RTO) at $800-1000{ }^{\circ} \mathrm{C}$. The gas flows were $500 \mathrm{sccm}$ nitrogen and 500 sccm oxygen at reduced pressure. The wafer temperature was monitor by pyrometry with a close loop control. The gate oxide

Manuscript received June 26, 2001; revised August 6, 2001. This work was supported by the National Science Council of Taiwan, R.O.C., (89-2218-E-002-082, 89-2218-E-002-054) and TSMC (Taiwan Semiconducto Manufacturing Company). The review of this letter was arranged by Editor $\mathrm{K}$ De Meyer.

The authors are with the Department of Electrical Engineering, National Taiwan University, Taipei, Taiwan, R.O.C. (e-mail: chee@cc.ee.ntu.edu.tw).

Publisher Item Identifier S 0741-3106(01)09413-7.



Fig. 1. SIMS profiles of the rapid thermal oxide with deuterium prebake.

thickness was measured by ellipsometry. NMOS diodes had Al gate electrodes with circular areas defined by photolithography.

\section{DEUTERIUM INCORPORATION}

In order to incorporate deuterium in the ultrathin oxide, the first kind process is to prebake the wafers in-situ at $1000{ }^{\circ} \mathrm{C}$ for two min in deuterium gas. Then the gate oxide is grown, followed by a $900{ }^{\circ} \mathrm{C}$ nitrogen post oxidation anneal for $10 \mathrm{~min}$. The secondary ion mass spectroscopy (SIMS) profiles of this deuterium prebake process shows a deuterium concentration of $2 \times 10^{19} \mathrm{~cm}^{-3}$ in the oxide as shown in Fig. 1 .

To further increase the deuterium incorporation, the second kind process is to add a deuterium post oxidation anneal for $10 \mathrm{~min}$ at $900{ }^{\circ} \mathrm{C}$ before the nitrogen anneal in the previous process. This yields a deuterium concentration of $2 \times 10^{20}$ $\mathrm{cm}^{-3}$ in Fig. 2. The deuterium concentration increases by one order of magnitude, as compared to the first kind process.

Since the Si wafers are cleaned by a HF dip before the transfer to the process chamber, the Si surface is hydrogen-terminated and the hydrogen passivation will prevent the deuterium incorporation in the oxide [9]. Therefore, the third kind process performs a thermal bake of the hydrogen-passivated wafer in the very high vacuum environment before the deuterium prebake. During the very high vacuum prebake $\left(<3 \times 10^{-6}\right.$ torr, maintained by a turbo pump), hydrogen can be removed from the $\mathrm{Si}$ surface. To estimate the hydrogen coverage after the very high vacuum prebake, the desorption rate $R_{d}$ was calculated by first order analysis [10] with the assumption of the initial coverage $\theta=1$, i.e., every silicon atom on the surface is bonded with hydrogen.

$$
R_{d}=-\frac{d \theta}{d t}=k_{d} \cdot \theta=\theta \cdot k_{d}^{0} \exp \left(-E_{d} / k T\right)
$$




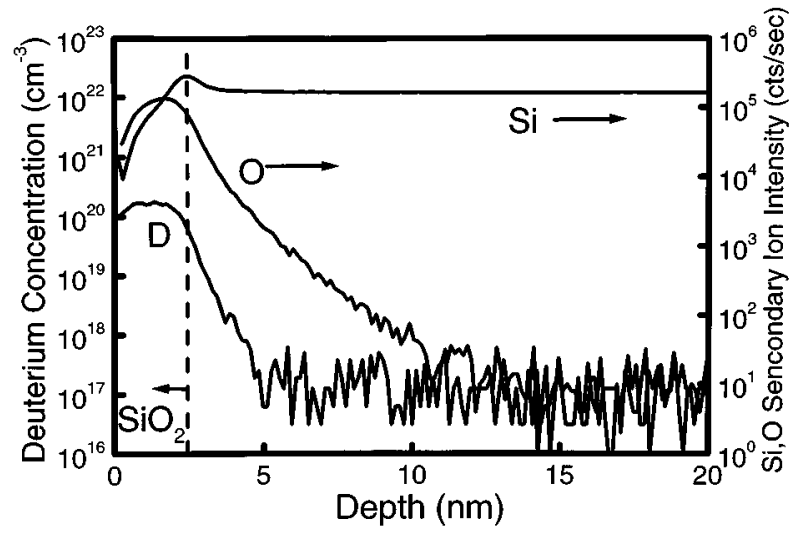

Fig. 2. SIMS profiles of the rapid thermal oxide with deuterium prebake and the post oxidation deuterium annealing.



Fig. 3. SIMS profiles of the rapid thermal oxide with very high vacuum prebake, deuterium prebake, and the post oxidation deuterium annealing.

where the activation energy $E_{d}$ and preexponential factor $k_{d}^{\circ}$ of hydrogen are $2.17 \mathrm{eV}$ and $2.2 \times 10^{12} \mathrm{~s}^{-1}$, respectively [10]. The hydrogen is almost completely removed by the very high vacuum prebake for two min at $1000{ }^{\circ} \mathrm{C}$, as indicated by the calculation. The deuterium incorporation in the oxide with very high vacuum prebake can reach as high as $9 \times 10^{20} \mathrm{~cm}^{-3}$ from the SIMS data in Fig. 3. However, the very high vacuum prebake also yields rough oxide with roughness up to $1.5 \mathrm{~nm}$ [11]. Since the roughness can also enhance the oxide reliability [12], the sole isotope effect on the oxide reliability can not be resolved. Therefore, all the following electrical measurements are based on the oxide prepared by the second kind process.

The grown oxide thickness by the deuterium process is $10-20 \%$ smaller, as compared to the hydrogen process. The hydrogen desorption rate is approximately 1.6 times the deuterium desorption rate [10], and this may be responsible for the low growth thickness of deuterium process. For all three processes, the deuterium atoms not only distribute at Si/oxide interface but also in the entire $\mathrm{SiO}_{2}$ layers (Figs. 1-3), very similar to the deuterium distribution of $\mathrm{D}_{2} \mathrm{O}$ pyrogenic oxide [13]. The incorporation of deuterium both at interface and bulk oxide plays an important role to suppress the electron trap creation. Note that the $\mathrm{D}_{2} \mathrm{O}$ pyrogenic oxidation [13] yields a much lower deuterium concentration of $1 \times 10^{19}$ $\mathrm{cm}^{-3}$, as compared to our process. Besides, to avoid the other

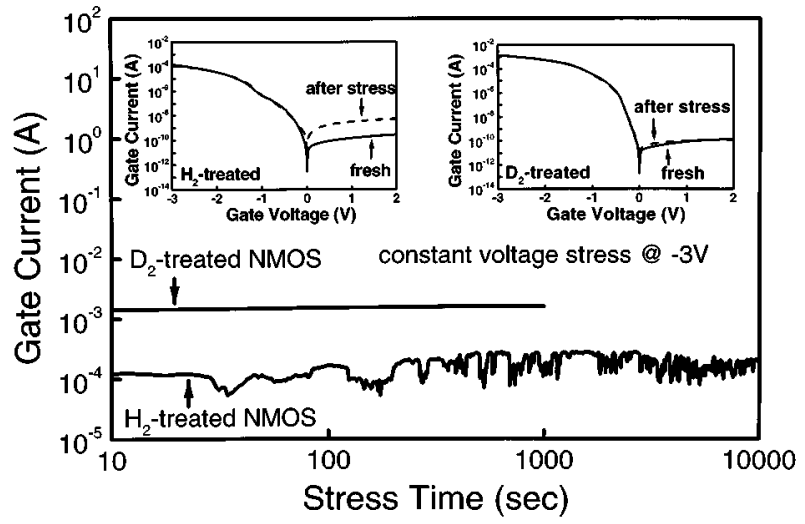

Fig. 4. Gate current versus stress time plot of $\mathrm{H}_{2}$-treated and $\mathrm{D}_{2}$-treated NMOS diodes with the area of $3 \times 10^{-4} \mathrm{~cm}^{2}$ under constant voltage stress with -3 V CVS for 10000 and $1000 \mathrm{sec}$, respectively. The insets are the $I-V$ characteristics of the devices before and after stress.

signal with mass-to-charge ratio of 2 such as $\mathrm{H}_{2}^{+}$, the SIMS profile of a $\mathrm{H}_{2}$-treated sample was also measured, and this signal was $\sim 1 \times 10^{18} \mathrm{~cm}^{-3}$, which was negligible as compared to the deuterium concentration. The $\mathrm{H}_{2}$-treated samples were processed using the same procedure except replacing deuterium with hydrogen.

\section{ELECTRICAL CHARACTERIZATION}

In order to observe the isotope effect, we use the second kind process to fabricate $\mathrm{H}_{2}$-treated and $\mathrm{D}_{2}$-treated devices to avoid the roughness effect produced by the very high vacuum prebake [11]. Fig. 4 shows the gate current variation as a function of stress time for $\mathrm{H}_{2}$-treated and $\mathrm{D}_{2}$-treated NMOS diodes with the area of $3 \times 10^{-4} \mathrm{~cm}^{2}$ under constant voltage stress (CVS). There is no apparent fluctuation in gate current during the stress of the $\mathrm{D}_{2}$-treated devices $\left(T_{o x}=1.6 \mathrm{~nm}\right)$, and the $I-V$ curves of the devices after $1000 \mathrm{sec}$ CVS at $-3 \mathrm{~V}$ is almost identical to the fresh one, as shown in the right inset of Fig. 4. For $\mathrm{H}_{2}$-treated devices $\left(T_{o x}=1.8 \mathrm{~nm}\right)$, the fluctuation in gate current under CVS implies that the degradation of oxide occurs and the inversion tunneling current increases significantly after the 10000 sec CVS at $-3 \mathrm{~V}$ (the left inset of Fig. 4). Note that the injection fluence $\left(Q_{i n j}\right)$ maintains the same (about $\left.4 \times 10^{3} \mathrm{coul} / \mathrm{cm}^{2}\right)$ for both the $\mathrm{H}_{2}$-treated and $\mathrm{D}_{2}$-treated devices, and the $\mathrm{D}_{2}$-treated devices have higher current densities. The $\mathrm{D}_{2}$-treated device still remains intact even after $5000 \mathrm{sec}$ stress (not shown here). We also perform the high-low frequency capacitance-voltage $(C-V)$ measurement on MOS diodes with thick oxide $\left(T_{o x}=4 \mathrm{~nm}\right)$ with the area of $3 \times 10^{-4} \mathrm{~cm}^{2}$ to extract the interface state densities $\left(D_{i t}\right)$ of the fresh devices and the stressed devices (Fig. 5). Note that we have difficulties to obtain reliable $C-V$ measurements on thin oxide $(<3 \mathrm{~nm})$. The extracted $D_{i t}$ increases by $\sim 7 \times$ in $\mathrm{H}_{2}$-treated devices after $15 \mathrm{sec}$ constant voltage stress at $-6 \mathrm{~V}$ since the $\mathrm{Si}-\mathrm{H}$ bonds were broken by the injected electrons. No apparent increase of $D_{i t}$ for $\mathrm{D}_{2}$-treated devices implies the isotope effect. Both devices with 4 -nm oxide break down during the constant current stress at $-1.5 \mu \mathrm{A}$ (the insets of Fig. 5). It is similar to the previous report that there is an isotope effect on $D_{i t}$, but no isotope effect on stress induced leakage current (SILC) for ultrathin oxide [14]. Note that the 




Fig. 5. Interface states density versus energy level of $\mathrm{H}_{2}$-devices (upper) and $D_{2}$-devices (lower) with the area of $3 \times 10^{-4} \mathrm{~cm}^{2}$ before and after stress. $D_{i t}$ increases approximately $7 \times$ after stress in $\mathrm{H}_{2}$ devices. No apparent increase of $D_{i t}$ in $\mathrm{D}_{2}$-treated devices is observed. The insets are the gate voltage variation during constant current stress $-1.5 \mu \mathrm{A}$.

isotope effect on SILC has been observed on the deuterium pyrogenic oxide, but not on the deuterium annealed thermal oxide [15].

Note that we have investigated the HF-dip only sample without $\mathrm{H}_{2}$ treatment as a control sample. The value of $D_{i t}$ is $2 \times 10^{12} \mathrm{eV}^{-1} \mathrm{~cm}^{-2}$ for the control sample, and reduces to 4 $\times 10^{11} \mathrm{eV}^{-1} \mathrm{~cm}^{-2}$ with $\mathrm{H}_{2}$ prebake two min at $1000^{\circ} \mathrm{C}$. The $D_{i t}$ can further decrease to be less than $1 \times 10^{11} \mathrm{eV}^{-1} \mathrm{~cm}^{-2}$ with both $\mathrm{H}_{2}$ prebake and $\mathrm{H}_{2}$ postoxidation anneal $\left(\mathrm{H}_{2} \mathrm{POA}\right.$ for $10 \mathrm{~min}$ ) at $900{ }^{\circ} \mathrm{C}$. However, the previous study reported that the degradation of the electrical properties was observed after the $\mathrm{H}_{2} \mathrm{POA}$ at temperature of $400-800^{\circ} \mathrm{C}$ [16]. This may attribute to different $\mathrm{POA}$ temperature, $\mathrm{N}_{2}$ POA, and oxidation conditions.

\section{CONCLUSIONS}

The deuterium distribution is not only at interface but also in the bulk oxide by these novel methods. The deuterium concentration as high as $2 \times 10^{20} \mathrm{~cm}^{-3}$ can be achieved by a process of deuterium prebake and deuterium post oxidation anneal. The isotope effects on constant voltage stress and $D_{i t}$ are observed for the deuterium-treated MOS device.

\section{REFERENCES}

[1] J. Maserijian and N. Zamani, "Behavior of the $\mathrm{Si} / \mathrm{SiO}_{2}$ interface observed by Fowler-Nordheim tunneling," J. Appl. Phys., vol. 53, no. 1, pp. 559-567, 1982.

[2] D. J. DiMaria and E. Cartier, "Mechanism for stress-induced leakage current in thin silicon dioxide films," J. Appl. Phys., vol. 78, no. 6, pp. 3883-3894, 1995.

[3] J. W. Lyding, K. Hess, and I. C. Kizilyalli, "Reduction of hot electron degradation in metal oxide semiconductor transistors by deuterium processing," Appl. Phys. Lett., vol. 68, no. 18, pp. 2526-2528, 1996.

[4] K. Hess, I. C. Kizilyalli, and J. W. Lyding, "Giant isotope effect in hot electron degradation of metal oxide silicon device," IEEE Trans. Electron Devices, vol. 45, pp. 406-416, Feb. 1998.

[5] J.-H. Wei, M.-S. Sun, and S.-C. Lee, "A possible mechanism for improved light-induced degradation in deuterium amorphous-silicon alloy," Appl. Phys. Lett., vol. 71, no. 11, pp. 1498-1500, 1997.

[6] C. G. Van de Walle and W. B. Jackson, "Comment on 'Reduction of hot electron degradation in metal oxide semiconductor transistors by deuterium processing,", Appl. Phys. Lett., vol. 69, no. 16, pp. 2441-2243, 1996.

[7] C.-H. Lin, M. H. Lee, and C. W. Liu, "Correlation between Si-H/D bond desorption and injected electron energy in metal-oxide-silicon tunneling diodes," Appl. Phys. Lett., vol. 78, no. 5, pp. 637-639, 2001.

[8] C. W. Liu, C.-H. Lin, M. H. Lee, S. T. Chang, Y. H. Liu, M.-J. Chen, and C.-F. Lin, "Enhanced reliability of electroluminescence from metal-oxide-silicon tunneling diodes by deuterium incorporation," Appl. Phys. Lett., vol. 78, no. 10, pp. 1397-1399, 2001.

[9] K. Arima, K. Endo, T. Kataoka, Y. Oshikane, H. Inoue, and Y. Mori, "Atomically resolved scanning tunneling microscopy of hydrogen-terminated Si(001) surface after HF cleaning," Appl. Phys. Lett., vol. 76, no. 4, pp. 463-465, 2000.

[10] K. Sinniah, M. G. Sherman, L. B. Lewis, W. H. Weinberg, J. T. Yates, Jr., and K. C. Janda, "Hydrogen desorption from the monohydride phase on Si(100)," J. Chem. Phys., vol. 92, no. 9, pp. 5700-5711, 1990.

[11] C. W. Liu, M. H. Lee, B.-C. Hsu, Y.-H. Liu, W. C. Chung, and W. W. Pai, "Correlation between oxide roughness and light emission intensity of metal-oxide-silicon light-emitting diodes," Appl. Phys. Lett., submitted for publication.

[12] C. W. Liu, C.-H. Lin, M. H. Lee, B. C. Hsu, K.-F. Chen, and C.-R. Shie, "Oxide roughness enhanced reliability of MOS tunneling diodes,", submitted for publication.

[13] Y. Mitani, H. Satake, H. Itoh, and A. Toriumi, "Highly reliable gate oxide under Fowler-Nordheim electron injection by deuterium pyrogenic oxidation and deuterated Poly-Si deposition," in IEDM Tech. Dig., 2000, pp. 343-346.

[14] D. Essenio, J. D. Bude, and L. Seimi, "Deuterium effect on interface state and SILC generation in CHE stress conditions: A comparative study," in IEDM Tech. Dig., 2000, pp. 339-342.

[15] Y. Mitani, H. Satake, H. Ito, and A. Toriumi, "A study of the effect of deuterium on stress-induced leakage current," Jpn. J. Appl. 2, vol. 39, no. 6B, pp. L564-L566, 2000.

[16] V. V. Afanas'ev and A. Stesmans, "Hydrogen-induced valence alternation state at $\mathrm{SiO}_{2}$ interfaces," Phys. Rev. Lett., vol. 80, no. 23, pp. 5176-5179, 1998. 